\title{
A FOTOGRAFIA COMO DOCUMENTO: COM A PALAVRA OTLET E BRIET
}

\section{PHOTOGRAPHY AS DOCUMENT: OTLET AND BRIET'S CONSIDERATIONS}

\author{
Izângela Maria Sansoni Tonelloa \\ Telma Campanha de Carvalho Madio ${ }^{b}$
}

\section{Resumo:}

Introdução: A quantidade e variedade de informações que veiculam em diferentes suportes e meios incitam uma preocupação, em especial, em relação aos documentos fotográficos, já que se constituem atualmente foco de interesse da área da Ciência da Informação. Nesse contexto, destacam-se as fotografias como fontes de informações geradoras de conhecimento e também como importante subsídio para pesquisa nas diferentes áreas.

Objetivo: Pesquisar os conceitos e definições que embasam a fotografia como documento em unidades de informação.

Metodologia: Pesquisa bibliográfica e documental.

Resultados: Pode-se afirmar mediante os significados acerca do termo documento, discorridas na literatura pelos autores pesquisados, que a fotografia corresponde aos pressupostos necessários para consubstanciar documento e fotografia em documento fotográfico.

Conclusões: Entende-se que esse estudo esclarece algumas questões relacionadas à fotografia como documento, no entanto, essa proposição suscita reflexões a respeito da importância do contexto de produção assim como sua relação imprescindível com os demais documentos, para que ela se consolide indiscutivelmente como documento fotográfico.

Descritores: Documento. Fotografia. Fotografia como documento.

\footnotetext{
${ }^{a}$ Doutoranda em Ciência da Informação pela Universidade Estadual Paulista Júlio de Mesquita Filho (Unesp). E-mail: izangela@uel.br

${ }^{\text {b }}$ Doutora em Ciências da Comunicação pela Universidade de São Paulo (USP). Professora da Universidade Estadual Paulista Júlio de Mesquita Filho (Unesp). E-mail: telmaccarvalho@marilia.unesp.br
} 


\section{INTRODUÇÃO}

A presença de imagens permeou a história da Humanidade nas suas mais diversas manifestações, pois o homem sempre e por diferentes meios e maneiras, buscou registrar e fixar acontecimentos do seu cotidiano, ou seja, representar objetos, eventos, paisagens, seres vivos, entre outros. Nesse sentido, a imagem conquistou, a cada dia, relevância como possibilidade de expressão e informação e, por esse motivo, o patrimônio informacional fotográfico tem aumentado consideravelmente.

Partindo dessa premissa, a organização desse conhecimento torna-se condição basilar para o desenvolvimento do ser humano e consequentemente da sociedade como um todo. Dessa forma, o documento fotográfico constitui em um registro de extrema importância para pesquisa nas diferentes áreas do conhecimento, sejam elas, administrativa, histórica, jurídica, acadêmica ou de cunho social.

A fotografia, portanto, foi conquistando aos poucos o status de fonte expressiva de informação e consolidando-se como documento em razão de atestar visualmente determinado fato. Vale lembrar que a informação, seja ela escrita, oral ou audiovisual, é elemento básico para a produção e disseminação do conhecimento.

Dada a relevância cada vez maior das informações na construção e disseminação do conhecimento, especialmente as expressas nos documentos fotográficos, surgem questionamento relevantes no que se refere à sua inserção e contextualização no arquivo.

Para o desenvolvimento dessa pesquisa buscou-se na literatura nacional e internacional já elaborada e publicada, os princípios e os conceitos aplicados para ratificar a fotografia como documento. Para isso foram utilizados materiais impressos e/ou não impressos, bibliográficos e/ou não bibliográficos e quaisquer outras fontes de informação, portanto, classifica-se esta pesquisa como bibliográfica e documental.

Nesse sentido, o presente artigo buscou na Ciência da Informação, mais especificamente nos pioneiros e ícones da documentação, como Paul Otlet e 
Suzanne Briet, embasamento teórico para fundamentar a importância das informações registradas na imagem fotográfica, bem como consolidar o fato de que a fotografia constitui-se, sem dúvida alguma, em documento.

\section{A FOTOGRAFIA}

A imagem utilizada como forma de registro das atividades humanas não é fato recente, remonta a época das cavernas. No entanto, a necessidade de registrar de forma mais fidedignamente possível as ações relevantes e memoráveis do homem no transcorrer da trajetória da humanidade, suscitou a busca e desenvolvimento de meios que atendessem a esse propósito.

Posteriormente, no contexto da Revolução Industrial, deu-se então o desenvolvimento em vários campos das ciências, propiciando a descoberta e criação de várias invenções que decididamente marcariam a história da humanidade, como, por exemplo, a forma química empregada para retratar pessoas, objetos e paisagens, com maior realismo, ou seja, a fotografia.

Conforme literatura especializada, em 1826, Joseph Nicephore Niepce foi a primeira pessoa a tirar uma fotografia, reproduzindo uma imagem inalterada por meio da ação da luz. Como esse processo heliográfico (desenho solar), tinha o inconveniente de ser muito demorado e resultar em uma imagem de pouca qualidade, o procedimento foi alterado por outro francês, Louis Daguerre, que aprimorou tal atividade, ao possibilitar, por intermédio de um método mais rápido e duradouro, uma imagem inalterável. (BUSSELLE, 1998)

De acordo com Walter Benjamin (1987, p.97) "[...] no instante em que Daguerre conseguiu fixar as imagens da câmara obscura, neste momento, os pintores haviam sido demitidos pelo técnico [...]", visto que, toda representação imagética da época era feita por pintores. Embora Daguerre tenha contribuído sobremaneira para o desenvolvimento da fotografia, foi um inglês, Fox Talbot, quem criou o primeiro processo prático para a produção de um número indeterminado de cópias do negativo original (BUSSELLE, 1998).

A partir disso, a fotografia realmente revolucionou o paradigma já instaurado de reproduzir objetos, pessoas e acontecimentos por meio da pintura, pois possibilitava uma nova forma de representá-los, em razão de 
mostrar, fixar e, ainda mais, viabilizar a reprodução da mesma imagem várias vezes e sem alterações. Vale salientar, que na época todo o registro da humanidade era preferencialmente textual e as imagens serviam meramente para ilustrá-lo. Durante muito tempo, essa foi a única e mais importante utilidade das fotografias, a ilustração.

No entanto, a fotografia foi conquistando espaço e, inegavelmente se deixando perceber como importante e, muitas vezes, insubstituível fonte de informações. Atualmente, é fato, as imagens estão presentes em todas as áreas do conhecimento desde as mais simples até as mais complexas, quais sejam, no cenário cultural, no científico, no social, permitindo além do compartilhamento de experiências não-verbalizadas, o conhecimento de culturas passadas uma vez que torna possível ao olhar-se uma imagem, conhecer e experimentar algo que não se viveu.

Em decorrência, a fotografia proporciona, de forma mais vívida e real, o resgate do passado, pois a imagem impressa no papel cristaliza um determinado momento, uma determinada ação, ao fazer um recorte particular de um acontecimento já passado, mas que se faz presente, pela imagem.

Como toda imagem, a fotografia carrega em si uma história e, olhar para a imagem representada, leva à reflexões a respeito daquele momento retratado e a intencionalidade do fotógrafo para que aquele acontecimento, aquela pessoa ou aquela paisagem não se perdesse. Sendo assim, tudo ali, naquela imagem, permanecerá como naquele instante. $O$ conteúdo informacional, o motivo se manterá nele. $O$ tempo parou naquele momento e permanecerá assim, representando o mesmo momento no qual foi registrado. Joly (1996, p.59) complementa as ideias citadas ao pontuar o papel da informação imagética, como "[...] instrumento de comunicação entre as pessoas, a imagem também pode servir de instrumento de intercessão entre 0 homem e o próprio mundo."

Portanto, as informações representadas nas fotografias, como qualquer informação independentemente dos elementos constitutivos das características do documento tais como suporte e gênero são apontadas por Barreto (2005, p.2) que: 
[...] quando adequadamente assimilada modifica o estoque mental de informações do indivíduo e traz benefícios ao seu desenvolvimento e ao desenvolvimento da sociedade em que ele vive. É como agente mediador na produção do conhecimento, que a informação mostra as suas qualidades, de forma e substância, como: estruturas simbolicamente significantes com a (in)tensão de gerar conhecimento no indivíduo em seu grupo e na sociedade.

Assim, ainda que as imagens por muito tempo fossem meras ilustrações ou somente complementos ilustrativos dos estoques das informações textuais, como já mencionado anteriormente, porém, atualmente são consideradas relevantes fontes informacionais.

Nesse cenário, a fotografia subverte as opiniões a seu respeito, e passa a ser vista como a forma mais adequada de representar não só as ciências, mas também os acontecimentos históricos, culturais e sociais e a constituir-se perante circunstâncias específicas em um elemento probatório.

Na esteira desse pensamento, Kossoy (2002, p.19) afirma que

[...] desde o seu surgimento e ao longo de sua trajetória, até os nossos dias, a fotografia tem sido aceita e utilizada com prova definitiva, 'testemunho da verdade' do fato ou dos fatos. Graças a sua natureza fisicoquímica - e hoje eletrônica- de registrar aspectos (selecionados) do real, tal como esses fatos aparecem, a fotografia ganhou elevado status de credibilidade.

Sontag (2004, p.16) também afirma que as fotografias "[...] fornecem um testemunho. Algo de que ouvimos falar, mas de que duvidamos parece comprovado quando nos mostram uma foto".

Em decorrência da atual concepção de fotografia como importante fonte de informações, bem como o aumento desse tipo de acervo, surge a necessidade de possibilitar seu acesso e consulta. Para que isso aconteça, são necessários procedimentos sistematizados que assegurem - em tempo hábil e com qualidade - a apropriação das informações contidas nas imagens. Dentre esses procedimentos, evidencia-se o ato de organizar de forma clara e concisa a informação inserida nas imagens fotográficas, atividade nuclear da Ciência da Informação, visto que, "[...] uma das suas atribuições é construir teorias e elaborar métodos para a transferência da informação, 
fundamentando o estabelecimento de canais formais para a comunicação da informação." (NOVELLINO, 1998, p.137).

McGarry (1999, p.11) destaca que "A informação deve ser ordenada, estruturada ou contida de alguma forma, senão permanecerá amorfa e inutilizável." Nesse contexto, fica claro que a informação registrada, armazenada e não organizada e também não disponibilizada, não desempenha seu papel fundamental: gerar novos conhecimentos para a evolução e crescimento de seres humanos comprometidos com a construção de uma sociedade e de um mundo melhor.

Não há dúvida de que, na sociedade contemporânea, a imagem fixa e em especial, a fotografia, é fato e presença marcante, seja em seu contexto cultural, educacional e social, proporcionando a difusão do conhecimento e da informação registrada a todos que tenham acesso a ela. Mediante as informações relativas à fotografia, visando a sua utilização como fonte fidedigna de conhecimento, percebe-se necessidade de defini-la como documento.

\section{O QUE É DOCUMENTO: COM A PALAVRA OTLET E BRIET}

O termo documento pode ter diferentes funções dependendo do contexto, seja no cotidiano, seja em áreas que o tem como objeto de estudo. Esse termo, no entanto, tradicionalmente refere-se a uma ação registrada em um suporte, porém, Bellotto (2004) amplia essa concepção ao considerar documento toda manifestação produzida pelo homem em razão de registrar uma atividade ou função seja ela jurídica, científica, artística, cultural ou ainda informacional, independente do meio de transmissão.

Lopez Yepes (1997, p.13) ressalta que

Desde el punto de vista de la evolución semántica, el documento puede ser considerado instrumento de cultura, instrumento de conocimiento y fijación de la realidad, mensaje en el proceso de información documental y fuente de conocimiento científico." 
O autor supracitado (2008) evidencia que para compreender e definir algo como documento é necessário considerar alguns aspectos como, o suporte e a informação registrada que se pretende transmitir. E para tenha valor como documento é essencial a percepção da sua finalidade, ou seja, porque foi criado e, também a sua possibilidade em proporcionar o acesso às informações e tomada de decisões

A Ciência da Informação constitui-se em uma disciplina que possui como escopo, a informação e em decorrência, todas as facetas relacionadas ao processo de produção, utilização, organização, armazenamento, recuperação, interpretação, transmissão, transformação. A partir disso, os primeiros documentalistas a se dedicarem a estudar a informação e seu suporte foram sem dúvida Paul Otlet (1934) e Suzanne Briet (1951) com obras consideradas básicas e fundamentais para a área da Ciência da Informação.

O Traité de Documentation: Le livre sur le livre - Théorie e Pratique (1934) de autoria de Paul Otlet (1868-1944), apresenta princípios, define teorias e conceitos a respeito do objeto da documentação, o documento, que é definido como todos os meios próprios para se transmitir, comunicar e propagar as informações e dados científicos, como livros, periódicos, catálogos; ou seja, os documentos de qualquer classe compostos de texto ou de imagens.

Otlet afirma também, a necessidade de uma ciência que aborde mais que a bibliografia, que segundo ele, consiste em descrever o documento, ou seja, uma ciência, que aliada a uma técnica, contemple todo desenvolvimento do documento, a bibliologia. A respeito dos termos "livro" e "documento" empregados por Otlet no Traité, percebe-se que se integram e resultam na definição de "[...] um suporte de uma determinada matéria e dimensão [...] com signos representativos de certos dados intelectuais." (OTLET, 1934, p. 43).

Nesse momento é importante ressaltar algumas considerações de Otlet (1934, p. 2 e 25) acerca de documento, que são:

[...] expressão escrita das ideias, instrumentos de sua fixação, conservação e circulação, os documentos são os intermediários obrigatórios de todas as relações entre os homens; [...] meio de transmitir dados informativos para 0 conhecimento dos interessados distantes no tempo e no espaço [...]; tudo aquilo que serve para registrar, transmitir e 
conservar a lembrança de uma coisa e para representar essa mesma coisa para ser utilizada para estudo. [...] registros gráficos e escritos os objetos em si também podem ser considerados se nos tornamos informados observando-os [...].

Fundamentado nisso, Otlet propõe um termo genérico para documento (biblion ou bibliograma ou documento) que abordaria todas as espécies: volumes, folhetos, revistas, artigos, carta, diagramas, fotografias, estampas, certificados, estatísticas além de discos e filmes. Portanto, insere-se como documento no Traité, a iconografia que é o documento que tem como característica de gênero: ser imagem. (OTLET, 1934).

Mais especificamente em relação à fotografia, o autor registra em sua obra

[...] a fotografia é pois a 'escrita com a ajuda da luz' e acrescenta que se pode dizer que a fotografia é uma maneira de escrever baseada em princípios matemáticos, físicos e químicos. A fotografia é a mais importante das máquinas intelectualmente inventadas pelo homem. Não só reproduz mas produz documentos e representa a realidade diretamente [...]. (OTLET, 1934, 199A).

A partir do exposto, não há dúvida que a obra de Paul Otlet contempla integral e satisfatoriamente o sentido do termo documento. Nesse momento, vale mencionar Montilla Peña (2013, p.58) que destaca essa obra como uma das maiores realizações como gênero literário, muito à frente de sua época, relacionada às áreas de biblioteconomia, arquivologia e museologia, expondo didaticamente suas ideias acerca de documento e documentação.

Diante disso, e a fim de discorrer e respaldar a respeito da fotografia como documento percebe-se a necessidade de abordar a obra de outro ícone: Suzanne Briet (1894-1989).

Briet foi uma das mais importantes seguidoras das ideias de Otlet e também inova e amplia a concepção de documento ao publicar um relevante manifesto modernista a respeito da natureza da documentação, intitulado "Qu'est-ce que la documentation?" Nesse documento ela resgata o sentido da palavra documento, evidenciando que esta, extrapola o documento textual quando afirma ser "[...] qualquer signo indicial concreto ou simbólico, 
conservado ou gravado, para fins de representar, de reconstituir ou provar um fenômeno físico ou intelectual." (BRIET, 1951, p. 7, tradução nossa).

Nesse contexto, Briet reafirma a ideia da permanência do documento como registro, pois sem o registro, não se tem a garantia de prova ou evidência, ou seja, não se pode comprovar um fato se não houver um registro dele.

Assim a autora enfatiza a importância do documento como evidência e para tanto questiona alguns objetos e o atributo deles como documento, como por exemplo: "Uma estrela é um documento? Um seixo rolado por uma torrente é um documento? Um animal vivo é um documento? Não. Mas são documentos as fotografias e catálogos de estrelas, pedras em um museu de mineralogia, os animais catalogados e expostos em zoológico". (BRIET, 1951, p.7, tradução nossa).

Buckland ao estudar a obra de Suzanne Briet, ratifica a afirmação acima ao esclarecer as condições definidas pela autora para que algo se constitua um documento: a materialidade - somente objetos e sinais físicos podem tornar-se documentos; intencionalidade - deve haver o propósito de se tratar o objeto como evidência; processamento - os objetos têm que ser processados, transformados em documentos; posição fenomenológica - os objetos devem ser percebidos como documentos. (BUCKLAND, 1997, tradução nossa)

No entanto, a indagação acerca do que realmente significa documento para Briet, foi a questão do antílope, uma vez que um antílope correndo selvagem nas planícies de África não é considerado um documento, pois nada foi registrado a respeito dele. No entanto se fosse capturado, levado para zoológico, seria um objeto de estudo o que resultaria em um documento. Assim tornou-se a partir do registro, uma evidência física, e pode ser utilizado por aqueles que o estudam. $O$ antílope catalogado é o documento inicial que gera a partir disso, outros documentos.

Complementado as ideias de Briet a respeito de documento, Lara (2010, p.45) destaca que [...] o documento é um signo físico ou simbólico, preservado ou registrado, cujo objetivo é representar, reconstruir ou demonstrar um fenômeno físico ou conceitual". 
A partir do exposto a respeito do termo documento, pode-se inferir de acordo com Briet "Um documento é uma prova que apoia um fato" (BRIET, 1951, p.9, tradução nossa).

Assim, Paul Otlet propõe para ao termo documento um domínio mais amplo, ou seja, qualquer registro do conhecimento independente do suporte, no qual se depreenda certa qualidade informacional. Já Briet, resgata o termo documento como prova, pois só o registo respalda uma circunstância, um acontecimento ou um fato e se registrado pode ser preservado, o que garante sua permanência no tempo e no espaço.

\title{
4 A FOTOGRAFIA COMO DOCUMENTO
}

Uma vez que, a fotografia é uma palavra que tem sua origem no idioma grego e que significa escrever com a luz (foto= luz e grafia= escrita), é razoável afirmar com base em Manini (2002), que documento é toda informação registrada em qualquer suporte, passível veicular e difundir o conhecimento e representa realização de uma atividade humana, portanto

\begin{abstract}
[...] o significado da própria palavra já a nomeia como documento. Desse modo, podemos tratar [...] a fotografia, como documento que transmite informação registrada em um suporte papel (fotografia analógica) ou eletrônico (fotografia digital), viabilizando a geração de conhecimento. Toda imagem tem um suporte e uma técnica [...]. Toda imagem é representativa, tem um suporte, é referencial, estética, artística, sintética, emotiva, objetiva e subjetiva. Além disso, a fotografia é real, pois documenta (BOCCATO; FUJITA, 2006, p. 86).
\end{abstract}

Logo, documento é um suporte, no qual foi fixada ou registrada uma ideia, uma noção ou uma mensagem. Essa premissa amplia a concepção de que só era considerada como documento a informação textual.

Dessa maneira, a fotografia como documento surge a partir do momento em que ela substitui 0 ato de registrar visualmente paisagens, pessoas, eventos, o que era feito por artistas e absorve uma das características essenciais de documentos de arquivo que é a sua natureza probatória já que 
conserva no tempo e no espaço o registro das ações ou fatos representados por meio da imagem.

Amar (2007, p. 63) ressalta que

A chegada da fotografia vai abalar estes modos de proceder, dado que ela é de imediato considerada completamente objectiva e verídica. O seu testemunho nunca é posto em dúvida. Ela vai ser, portanto, a 'testemunha fiel' de todos os factos importantes.

Nesse contexto, a fotografia subverte as opiniões a seu respeito, e passa a ser vista como a forma mais adequada de representar, não só as ciências, mas também os acontecimentos históricos, culturais e sociais.

Dessa forma a fotografia passou não só a substituir pinturas pessoais e particulares, como também a registrar fatos e acontecimentos sociais, passando assim a fazer parte dos acervos documentais.

Nesse contexto, Kossoy (2007, p.41) afirma que, em relação à fotografia

Trata-se dos indícios existentes na imagem (iconográficos), e que, acrescidos, de informações de natureza histórica, geográfica, geológica, antropológica, técnica, a carregam de sentido. Um conjunto de informações escritas e visuais que, associadas umas às outras, nos permitem datar, localizar geograficamente, identificar, recuperar enfim, micro-histórias de diferentes naturezas implícitas no documento.

Dessa forma, pode-se afirmar que a fotografia é um documento, e foi incorporada às instituições como bibliotecas, museus e a arquivos embora diferentemente e cumprindo funções próprias em cada local, como muito bem aponta os autores Otlet e Briet.

Manini (2010, p.19) acrescenta que: "A fotografia é um documento ímpar e diferenciado dentro das instituições, onde o documento escrito tem sido o objeto principal".

Albuquerque e Madio (2013) corroboram ao afirmarem que a inserção e obviamente a organização das fotografias como documento em instituições como arquivos, bibliotecas e museus demandam formas peculiares, pois essas instituições possuem especificidades que as diferenciam e outras que as aproximam. 
Em relação ao valor da fotografia como documento para a reconstrução de fatos passados, devem ser buscadas também outras fontes documentais e não somente as textuais, pois:

[...] a história faz-se com documentos escritos sem dúvida. Quando estes existem. Mas pode fazer-se, deve fazer-se sem documentos escritos, quando não existem. Com tudo o que a habilidade do historiador lhe permite utilizar para fabricar o seu mel, na falta das flores habituais, Logo, com palavras. Signos. Paisagens e telhas. [...] Com os exames de pedras feitos pelos geólogos e com as análises de metais feitas pelos químicos. Numa palavra, com tudo o que pertencendo ao homem, depende do homem, serve ao homem, exprime o homem, demonstra a presença, a atividade, os gostos e as maneiras de ser do homem. [...]. (FEBVRE, apud LE GOFF, 2003, p.530).

De acordo com Buckland (1997, p.805) as ideias de Paul Otlet e Suzanne Briet acerca de documento, seja definindo conceitos ou condições para a sua proposição ampliam a noção de documento. Para tal, Otlet (1934, p.43) afirma que "Os registros gráficos e escritos, os objetos em si também podem ser considerados como 'documentos' se, observando-os, obtiver informações. Por exemplo, objetos tais como artefatos, achados arqueológicos, modelos, jogos educativos e obras de arte." E nessa direção Briet (1951 p.10) destaca como documento "[...] qualquer índice concreto simbólico, preservado e registrado para representar, reconstituir ou demonstrar um fenômeno físico ou intelectual". Dessa forma, os autores embasam a pertinência e valor da fotografia como documento, em razão dela corresponder aos pressupostos, necessários para consolidar as informações registradas em um suporte, como documento.

\section{CONSIDERAÇÕES FINAIS}

Atualmente a fotografia, em muitas situações, parece ser a melhor maneira de representar lugares, pessoas, fatos e acontecimentos. Nesse sentido, caracteriza-se como um dos meios mais eficazes e criativos para identificar, reconhecer e validar fatos passados por meio da imagem, em virtude de possibilitar, a captura momentânea da imagem que se queira registrar e, posteriormente resgatar. 
Reconhecer, organizar e preservar os registros do conhecimento é condição precípua para se perpetuar a história, a aquisição de conhecimento bem como o desenvolvimento do ser humano. Nessa perspectiva, as fotografias constituem-se, entre outros aspectos, em documentos de extrema importância para as diversas áreas do conhecimento.

Para Guran (1992, p.15) "[...] a fotografia é uma extensão de nossa capacidade de olhar, e se constitui em uma técnica de representação da realidade que, pelo seu rigor e particularismo, se expressa através de uma linguagem própria e inconfundível".

Dessa forma, evidencia-se a importância da fotografia no âmbito da Ciência da Informação como documento. No entanto é necessário responsabilidade em relação às atividades relacionadas aos procedimentos de identificação e determinação do contexto de produção assim como os processos que se relacionam com as informações expressas na fotografia,

Dada a importância das informações contidas na fotografia, esse estudo visou pesquisar a literatura pertinente, com ênfase nas obras de Paul Otlet e Suzanne Briet, fundamentos para subsidiar alguns preceitos e ações que consolidassem à fotografia o status de "documento fotográfico".

Revisitando Paul Otlet e Suzanne Briet fica evidente que o autor em sua obra amplia e acrescenta os muitos objetos que podem ser considerados documentos, principalmente pelo fato de proporcionarem a aquisição do conhecimento, a quem dele necessite. Vale ressaltar, que Otlet foi o precursor, da inserção da fotografia na concepção de documento, ao considerar as informações imagéticas, como tal.

Em relação a Briet (1951 p.10) o documento é evidenciado como "qualquer índice concreto simbólico, preservado e registrado para representar, reconstituir ou demonstrar um fenômeno físico ou intelectual." A autora caracteriza o documento pela sua condição de materialidade, ou seja, o registro ou qualquer objeto que se queira registrar; a intenção de que tal objeto seja prova de algo; procedimentos para que se torne documento e a percepção do objeto como documento. 
Concluindo as contribuições de Otlet e Briet acerca do termo documento, é razoável dizer que se complementam, pois ambos ampliam o termo documento, incluindo aí tudo que seja capaz de informar, ser registrado e permanecer no tempo e no espaço.

Pode-se afirmar, como resultado dessa pesquisa que mediante os significados acerca do termo documento, discorridas na literatura pelos autores pesquisados, que a fotografia corresponde aos pressupostos necessários para consubstanciar documento e fotografia em documento fotográfico. Espera-se que esse estudo possa contribuir com a área da Ciência da Informação pois elucida algumas indagações concernentes à fotografia como documento.

À guisa de encerramento, entende-se que esse estudo esclarece algumas questões relacionadas à fotografia como documento e que essa proposição suscite reflexões a respeito da importância do contexto de produção bem como de sua relação imprescindível com os demais documentos, condição sine qua non para que ela se consolide indiscutivelmente como documento fotográfico.

\section{REFERÊNCIAS}

AMAR, P. J. História da fotografia. Lisboa: Edições 70, 2007.

BARRETO, A. A. A estrutura do texto e a transferência da informação.

DataGramaZero - Revista de Ciência da Informação, Rio de Janeiro, v.6, n.3, jun. 2005. Disponível em:

$<$ http://www.brapci.inf.br/index.php/article/view/0000007747/ec0d3b37d3c8ada 090e947a912ae0916/>. Acesso 07 mar. 2017.

BELLOTTO, H. L. Arquivos permanentes: tratamento documental. 2. ed. rev. e ampl. Rio de Janeiro: Editora FGV, 2004.

Documento significação na trajetória epistemológica e da Ciência da Informação. In: FREITAS, L. S. de; MARCONDES, C. H.; RODRIGUES,A.C. (Orgs) Da gênese à função: o documento de arquivo como informação e testemunho. Niterói: EdUFF, 2010. p. 161-174.

BENJAMIN, W. Pequena história da fotografia. In: Magia e técnica, arte e política: ensaios sobre literatura e história da cultura. 7. ed. São Paulo: Brasiliense, 1994. p. 91-107. (Obras Escolhidas, v.1). 
BOCCATO, V. R. C.; FUJITA, M. S. L. Discutindo a Análise Documental de Fotografias: uma síntese bibliográfica. Cadernos de Biblioteconomia Arquivística e Documentação. Lisboa, n. 02, p. 84 - 100, 2006.

BUSSELLE, M. Tudo sobre fotografia. 8. ed. São Paulo: Pioneira, 1998.

BRIET, S. Qu'est-ce que la documentation? Paris: Éditions Documentaires Industriales et Techniques, 1951. 48p. Disponível em:

$<$ http://martinetl.free.fr/suzannebriet/questcequeladocumentation > Acesso em: 07 maio 2017.

BUCKLAND, M. What is a "document "? Journal of the American Society of Information Science, vol. 48, n.9, p.804-809, 1997. Disponível em: $<$ http://people.ischool.berkeley.edu/ buckland/whatdoc.html>. Acesso em: 10 jun. 2017.

BUSSELLE, M. Tudo sobre fotografia. 8. ed. São Paulo: Pioneira, 1998.

JOLY, M. Introdução à análise da imagem. Campinas: Papirus, 1996.

GURAN, M. Linguagem fotográfica. In: GURAN, M. Linguagem fotográfica e informação. Rio de Janeiro: Rio Fundo, 1992. p. 15 - 22.

KOSSOY, B. Realidades e ficções na trama fotográfica. 3. ed. São Paulo: Ateliê Editorial, 2002.

Os tempos da fotografia. São Paulo: Ateliê, 2007.

LE GOFF, J. História e memória. 5. ed. Campinas: Editora da UNICAMP, 2003.

LARA, M. L. G. de. Documento significação na trajetória epistemológica e da Ciência da Informação. In: FREITAS, L. S. de; MARCONDES, C. H.; RODRIGUES, A.C. (Orgs) Documento gênese e contexto de uso. Niterói: EdUFF, 2010. p. 35-56

LOPEZ, A. P. A. Organização arquivística de documentos imagéticos e pesquisa histórica. Cadernos de Metodologia e Técnica de Pesquisa, Maringá (PR), 7 (1996) 189-198.

LOPEZ YEPES, J. Notas acerca del concepto y evolución del documento contemporâneo.In: VII Jornadas Científicas sobre Documentación

Contemporánea. Madrid, Departamento de Ciencias y técnicas historiográficas, UCM, 2008, p. 273-279. < Disponível em:

$<$ http://www.ucm.es/centros/cont/descargas/documento11910.pdf $>$. Acesso em: 16 ago. 17.

Reflexiones sobre el concepto de documento ante la revolución de la información: ¿un nuevo profesional del documento? Scire: representación y organización del conocimiento. Zaragoza: 1997, v. 3, n. 1. Disponível em: 
$<$ http://ibersid.eu/ojs/index.php/scire/article/view/1064 > Acesso em: 15 jul. 2017.

MCGARRY, K. O contexto dinâmico da informação. Brasília: Briquet de Lemos/Livros, 1999.

MADIO, T. C. de C.; FUJITA. M. S. L. Importância da gênese documental para identificação de acervos fotográficos. Revista de sistema de información y documentación. Zaragoza: 2008, v. 2. p. 251-261. Disponível em:

$<$ http://www.ibersid.eu/ojs/index.php/ibersid/index> Acesso em: 08 jun.2017.

MANINI, M. P. A fotografia como registro e como documento de arquivo. In: MANINI, M. P.; MARQUES, O. G.; MUNIZ, N. C. (orgs). Imagem, memória e informação. Brasília: Ícone Editora e Gráfica, 2010, p. 11 - 31.

Análise Documentária de fotografias: um referencial de leitura de imagens fotográficas para fins documentários. 2002. 231f. Tese (Doutorado em Ciências da Comunicação) Universidade de São Paulo, São Paulo, 2002.

Análise Documentária de imagens. Inf. \& Soc.: Est. João Pessoa, v. 11, n. 1 , p. $128-135,2001$.

MONTILLA PEÑA, L.J. El tratado de documentación de Paul Otlet: una exposición metacientifica. Disponível em

$<$ https://biblios.pitt.edu/ojs/index.php/biblios/article/view/93/166>. Acesso em: 15 jul. 2107.

NOVELLINO, M. S. F. A linguagem como meio de representação ou de comunicação da informação. Perspectiva em Ciência da Informação. Belo Horizonte, v. 3, n. 1, p. 137 - 146, jul./dez., 1998.

OTLET, P. (1934). Traité de documentation: le livre sur le livre: théorie et pratique. Bruxelles: Mundaneum Disponível em:

$<$ http://lib.ugent.be/fulltxt/handle/1854/5612/Traite de documentation ocr.pdf> Acesso em: 2 maio 2017.

SONTAG, S. Sobre fotografia. São Paulo: Companhia das Letras, 2004.

\title{
PHOTOGRAPHY AS DOCUMENT: OTLET AND BRIET'S CONSIDERATIONS
}

\begin{abstract}
:
Introduction: The amount and variety of information that are conveyed in different media and means incite a concern, especially in relation to photographic documents, since they are currently the focus of interest of the Information Science field. In this context, this paper emphasizes the role of photographs as sources of information capable of generating knowledge as well as an important aid for research in different
\end{abstract}


areas. Objective: The main goal of this study was to research the concepts and definitions underpinning the photograph as a document in information units. Methodology: Bibliographic and documentary research. Results: It can be affirmed through the meanings about the term document discussed in the literature by the researched authors that the photograph corresponds to the assumptions necessary to substantiate document and photograph in photographic document. Conclusions: It is understood that this study clarifies some issues related to photograph as a document; however, this proposition raises reflections about the importance of the production context as well as its essential relationship with other documents, so that it is indisputably consolidated as a photographic document.

Descriptors: Document. Photography. Photography as document.

\title{
LA FOTOGRAFÍA COMO DOCUMENTO: CON LA PALABRA OTLET Y BRIET
}

\begin{abstract}
RESUMEN:
Introducción: La cantidad y variedad de informaciones que fluyen en diferentes soportes y medios incitan una preocupación, en especial, en relación a los documentos fotográficos, ya que se constituyen actualmente en centro de interés en áreas como Ciencias de la Información. En ese contexto, se destacan las fotografías como fuentes de informaciones generadoras de conocimiento y también como importante ayuda de investigación en las diferentes áreas. Objetivo: Estudiar los conceptos y definiciones que analizan la fotografía como documento en unidades de información. Metodología: Se realizó un estudio bibliográfico y documental. Resultados: Se puede afirmar por medio de los significados acerca del término documento, analizados en la literatura por los autores mencionados anteriormente, que la fotografía corresponde a premisas necesarias que constituyen al documento y a la fotografía en documento fotográfico. Conclusiones: Se entiende que este estudio, esclarece algunos puntos relacionados con la fotografía como documento, sin embargo, esta propuesta suscita reflexiones respecto de la importancia del contexto de la producción, así como su relación imprescindible con los demás documentos, para que ella se consolide indiscutiblemente como documento fotográfico.
\end{abstract}

Descriptores: Documento. Fotografía. Fotografía como documento. 